\title{
GESTÃO E FINANÇAS PARA ENGENHARIA DE PRODUÇÃO: ANÁLISE COMPARATIVA DA PERIODIZAÇÃO DE DISCIPLINAS EM 10 UNIVERSIDADES BRASILEIRAS
}

\author{
Maria Eliza C. Lazzaretti (UNIVERSIDADE FEDERAL DO PARANÁ) \\ liza.pugli@gmail.com \\ Vitória de Melo Schroeder (UNIVERSIDADE FEDERAL DO PARANÁ) \\ vitoria.melos@outlook.com
}

Ruth M. Hofmann (UNIVERSIDADE FEDERAL DO PARANÁ) ruthofmann@gmail.com

\section{Resumo}

A Engenharia de Produção tem suas origens junto à Administração Científica e, atualmente, conta com 10 grandes áreas estabelecidas pela Associação Brasileira de Engenharia de Produção (ABEPRO). Além de conteúdos voltados a melhoria produtiva e logística, inclui-se em seu currículo assuntos como economia e administração. Estes últimos, entretanto, são abordados diferentemente entre as universidades públicas no Brasil, visto que os cursos possuem duração, em geral, de 10 semestres e precisam contemplar todo o currículo estabelecido. Assim, espera-se que, de acordo com a oferta de cada instituição de ensino, o aluno egresso possa apresentar habilidades relacionadas à análise de investimentos e custos, compreender a Teoria Econômica e ter competência para dirigir um projeto ou organização, além de assegurar o controle das finanças pessoais. Visando elencar a quantidade de matérias voltadas à economia e gestão e analisar a periodização das disciplinas, o presente estudo determinou 10 instituições de ensino públicas na região Sul do Brasil como um espaço amostral e obteve, através de métodos estatísticos, possíveis relações.

Palavras-Chaves: ensino de Engenharia de Produção; periodização de disciplinas; gestão e finanças para Engenharia de Produção.

\section{Introdução}

A adequação do currículo dos cursos de graduação às demandas do mercado de trabalho é uma preocupação recorrente de instituições de ensino superior (MELLO; SANTOS, 2015. SAUNDERS; SAUNDERS, 2004). Promover atualizações no conteúdo de ementas, incluir disciplinas novas (obrigatórias e optativas), adotar novos métodos e técnicas de ensino são iniciativas que buscam fazer frente aos desafios que se impõe no esforço de promover a melhoria no ensino em Engenharia (MELLO; SANTOS, 2015). 
O curso de Engenharia de Produção sofreu algumas modificações desde o advento do que ficou conhecido como seu berço: a Administração Científica, modelo formulado pelos engenheiros Frederick Taylor e Frank Bunker Gilbreth, pela psicóloga Lillian Moller e dentre outros pesquisadores. Embora a gerência da produção tenha sido o principal foco durante boa parte do século XX, conhecimentos relacionados à Engenharia Econômica, como a matemática financeira e a análise de custos e investimentos, introduziram um novo campo de estudo (PIRATELLI, 2005). E somente após março de 2002, o Ministério da Educação (MEC) estabeleceu que a grade deveria ser composta por $30 \%$ de matérias da grade comum à todas as engenharias, $15 \%$ de específicas e o resto constituído por disciplinas ligadas à profissão.

Adequar o currículo às necessidades do mercado de trabalho, assim como às determinações do MEC é um processo burocraticamente complexo que pode levar tempo significativo de implementação nas universidades brasileiras. Ajustes e reformas curriculares devem ser pautadas, assim, por uma análise criteriosa das necessidades de adaptação. Parte importante da análise se dá mediante comparação de currículos de universidades de referência, ou, em outros termos, um processo de benchmarking.

Analisando, por exemplo, instituições com um grau de excelência no ensino de Engenharia de Produção no Brasil, é válido destacar a Universidade Federal do Rio de Janeiro (UFRJ), ocupando, atualmente, a $5^{\text {a }}$ posição no Ranking Universitário Folha (RUF), com nota igual a 61,16 em qualidade de ensino. O curso de Engenharia de produção da UFRJ oferece como base o núcleo comum, exigido pela Secretaria de Regulação e Supervisão da Educação Superior, e em seguida permite que o discente opte por cursar entre as áreas de Gestão da Produção e Engenharia Econômica.

Ainda que as determinações do MEC em relação à composição da grade curricular em Engenharia de Produção seja de abrangência nacional, deve-se ponderar o sucesso das instituições na inserção de seus alunos no mercado de trabalho requer que seu currículo esteja alinhado às necessidades regionais apresentadas pelas empresas contratantes. A configuração econômica regional, expressa no perfil das empresas, pode ser uma variável relevante na composição do currículo.

Além disso, a construção do currículo também deve se pautar pelas escolhas institucionais em relação à posição de disciplinas específicas em períodos iniciais, intermediários ou finais do curso. Essas escolhas são norteadas por critérios didático pedagógicos, operacionais e mercadológicos utilizados pelas instituições de ensino superior. É nesse contexto que o 
objetivo deste artigo é apresentar uma análise comparativa da periodização de disciplinas de gestão e finanças em 11 cursos de graduação em Engenharia de Produção no do sul do Brasil. Pretende-se, com o artigo, identificar semelhanças e diferenças no que se refere à posição das disciplinas na cronologia dos cursos.

O trabalho está estruturado em quatro seções além desta introdução. A seção 2 apresenta a revisão da literatura sobre o ensino de disciplinas de gestão e finanças para Engenharia. A seção 3 apresenta os procedimentos metodológicos adotados no trabalho. A seção 4 expõe e discute os resultados obtidos, cabendo à última seção a apresentação de considerações finais do trabalho.

\section{Ensino de gestão e finanças na formação de engenheiros}

Em termos gerais, o principal objetivo do ensino de economia na graduação é permitir que os estudantes sejam capazes de pensar como economistas (SIEGFRIED et. al. 1991). A contribuição do ensino de Economia para a formação em Engenharia há muito tem sido contemplada na literatura acadêmica. Seja para ampliar a visão dos engenheiros, expondo a relação da engenharia com outras atividades, seja para criar o hábito de pensar em termos de grupos, o ensino de economia contribui para a percepção do próprio objetivo da Engenharia: em último caso, o resultado do trabalho de Engenharia se expressa em termos econômicos (HAYFORD, 1917).

Para autores como Hayford (1917), os estudantes de Engenharia deveriam ser apresentados aos conteúdos de Economia seguindo a mesma abordagem de ensino que estudantes de outras áreas, para que com isso os engenheiros não sejam prejudicados em sua formação. Devem-se reconhecer, entretanto, os desafios pedagógicos decorrentes da especificidade do ensino de Economia para Engenheiros. Cairncross (1988, p. 213), por exemplo, ressalta que:

Ensinar economia aos engenheiros não é fácil. Para muitos deles, o assunto é muito amorfo e parece muito com o senso comum que eles sentem que já possuem. Eles tendem a mostrar impaciência com o assunto, a menos que este possa estar em termos matemáticos precisos, o que eles consideram ser necessário para qualquer disciplina que se pretenda científica. $\mathrm{O}$ resto pode ser descartado como "apenas bom senso" ou "trivial", porque parece muito amorfo e carente de rigor. (...) [Contudo] São precisamente os aforismos simples da economia que são mais facilmente e tolamente ignorados: por exemplo, "não existe almoço grátis", você não pode comer seu bolo e comê-lo, "os custos reais são oportunidades perdidas". Por outro lado, as equações e funções apresentadas para o engenheiro 
podem deturpar a incalculabilidade do comportamento humano. (CAIRNCROSS, 1988).

O potencial das disciplinas de economia e finanças não se restringe à atuação profissional dos Engenheiros. Há evidências de que estudantes que tiveram disciplinas de economia na faculdade se endividam menos com empréstimos estudantis e com financiamento de veículos. Quando financiam automóveis, conseguem parcelas mensais menores, e quando assumem financiamento estudantil o fazem para um valor relativamente menor (BOSSHARDT; WALSTAD, 2018).

O engenheiro, com acesso a conteúdos econômicos, é capaz de não somente lidar com as flutuações do mercado e minimizar os custos de seus projetos, como também ter uma vantagem no mercado de trabalho. A engenharia econômica, contudo, deve ser ministrada com um material interdisciplinar dentro das Universidades, visto que é preciso maximizar a retenção de conteúdos pelo aluno por um longo período de tempo e atrair sua atenção para a disciplina (ZOGHI, 2015).

Para Zoghi (2015), o ensino financeiro deve ser aprimorado, julgando por sua importância na formação dos engenheiros. $\mathrm{O}$ autor sugere o investimento nas práticas educacionais, como a Taxonomia de Bloom, que aborda diferentes métodos de passar o conteúdo para os discentes, estudos coletivos, pois permitem o desenvolvimento do cognitivo individual, uso de computadores e, também, uso de aplicativos que permitam que as dúvidas sejam sanadas anonimamente.

Embora a aplicação de provas ainda seja o método mais comum em que os alunos são avaliados nas disciplinas, nota-se que há uma grande necessidade de ampliar a metodologia de ensino, principalmente no campo das finanças, buscando aproximar o estudo da realidade. Silva, Stano e Rezende (2012) concluem que uma forma de realizar tal aproximação seria, por exemplo, abordar conteúdos como a Economia Brasileira, diversificando os estudos com a utilização de leituras complementares.

O estudo também foi debatido por autores como Evans, Nachtmann e Needy, que alegam uma estagnação no ensino de finanças. Eles analisaram uma experiência realizada com uma turma, dividindo a em dois grupos: enquanto uma parte respondeu um quiz sobre economia, antes de a aula ser ministrada pelo professor, outra teve acesso posteriormente. Os resultados mostram, contudo, que apesar do segundo grupo ter aprendido o conteúdo em sala, suas notas foram menores, pois o primeiro teve que buscar entendê-lo sozinho, enfatizando a teoria de que o 
ensino econômico deve estimular a curiosidade individual (EVANS; NACHTMANN; NEEDY, 2010).

Ainda no campo da Engenharia, dessa vez dando espaço à ênfase em Produção, a Gestão Econômica é uma das 10 áreas do curso e deve ser abordada durante a graduação, englobando matérias como Engenharia Econômica, Análise de Investimentos e Gestão de Custos, seguindo as definições estabelecidas pela ABEPRO (PIRATELLI, 2005) e contribuindo para a formação de um profissional crítico, capaz de resolver questões financeiras relacionadas a um projeto (SILVA; STANO; REZENDE, 2002).

Essa formação permite uma análise criteriosa do processo produtivo e uma redução de custos no ambiente de trabalho e, para garantir que o egresso tenha uma noção geral, Borges e Tachibana (2004) alegam que o ensino de finanças deve ter aspectos tanto da economia positiva, que trata da economia descritiva, teoria econômica e análise econômica, quanto aspectos da economia normativa, para que as normas de condutas estabelecidas culturalmente permitam que o engenheiro interprete os cenários possíveis.

\section{Metodologia}

Visando atingir o objetivo deste trabalho, o artigo se caracteriza como uma pesquisa qualiquantitativa de caráter exploratório e expõe de dados secundários. Quanto aos procedimentos metodológicos, o trabalho pautou-se pelas seguintes etapas:

a) Levantamento das Universidades Públicas, da região Sul do Brasil, que oferecem o curso de Engenharia de Produção. Para isso, utilizou-se como critério inicial, o Ranking de Universidades da Folha de 2019 (RUF), que leva em consideração os seguintes indicadores: Avaliação no MEC, pesquisa, ensino, mercado, internacionalização e inovação.

b) Análise da grade curricular básica de Engenharia de Produção exigida pela Secretaria de Regulação e Supervisão da Educação Superior;

c) Seleção das instituições, descartando qualquer curso com alguma ênfase: civil, mecânica, sistemas, software, etc. A ausência de informações específicas sobre ementas de disciplinas levou à exclusão de instituições como a Universidade de Estadual do Paraná (UNESPAR); 
d) Estabeleceu-se que seria analisada uma amostra com cursos de 10 períodos de modalidade presencial, totalmente gratuitos, excluindo, assim, a Universidade Tecnológica Federal do Paraná (UTFPR) - Campus Medianeira por ofertar 9 semestres e, tanto o Centro Universitário Para o Desenvolvimento do Alto Vale do Itajaí (UNIDAVI), quanto o Centro Universitário de União da Vitória (UNIUV) por coletar mensalidade dos docentes;

e) Em seguida, todos os sites das graduações fixadas foram levantados, visando buscar a quantidade de matérias que envolvem finanças e contabilidade, bem como o período de cada uma e a carga horária.

f) Qualquer carga horária complementar ou matérias optativas focadas em economia foram desconsideradas;

g) Posteriormente, após a análise dos resultados e da ausência de uma possível relação, passou-se a verificar a quantidade de disciplinas de economia em cada um dos cursos, independente da posição no ranking, levantando suas ementas.

h) Finalmente, utilizando o Excel, elaborou-se uma tabela com as estatísticas descritivas para todas as disciplinas, analisando a moda, mediana, média, desvio padrão, curtose, assimetria, variância, entre outros cálculos.

\section{Resultados e discussão}

A partir da análise das ementas, foram consideradas disciplinas de gestão e finanças, no caso das universidades do Rio Grande do Sul, matérias como Engenharia Econômica, Contabilidade de Custos de Produção e Fundamentos da Administração, conforme consta nos resultados.

Quadro 1 - Disciplinas ofertadas, carga horária e periodização nos cursos públicos de Engenharia de Produção no Rio Grande do Sul

\begin{tabular}{|c|c|c|c|c|}
\hline Universidades & Estado & Disciplinas & $\begin{array}{c}\text { Perío } \\
\text { do }\end{array}$ & $\begin{array}{c}\text { Carga } \\
\text { Horária }\end{array}$ \\
\hline $\begin{array}{c}\text { Universidade Federal do Rio Grande do } \\
\text { Sul (UFRGS) }\end{array}$ & \multirow{2}{*}{ RS } & Análise Gerencial de Custos I & $6^{\circ}$ & 60 \\
\cline { 3 - 5 } & & Engenharia Econômica e & $7^{\circ}$ & 60 \\
& & Análise Multicriterial & & 30 \\
\hline
\end{tabular}




\begin{tabular}{|c|c|c|c|c|}
\hline \multirow{4}{*}{$\begin{array}{l}\text { Universidade Federal de Santa Maria } \\
\text { (UFSM) }\end{array}$} & \multirow[t]{4}{*}{$\mathrm{RS}$} & Engenharia Econômica I & $2^{\circ}$ & 60 \\
\hline & & Introdução à Administração & $2^{\circ}$ & 30 \\
\hline & & Engenharia Econômica II & $3^{\circ}$ & 60 \\
\hline & & Custos de Produção & $6^{\circ}$ & 60 \\
\hline \multirow{3}{*}{$\begin{array}{l}\text { Universidade Federal de Pelotas } \\
\text { (UFPEL) }\end{array}$} & \multirow[t]{3}{*}{$\mathrm{RS}$} & Economia Industrial & $1^{\circ}$ & 30 \\
\hline & & Engenharia Econômica & $5^{\circ}$ & 90 \\
\hline & & $\begin{array}{l}\text { Contabilidade e Custos da } \\
\text { Produção }\end{array}$ & $7^{\circ}$ & 60 \\
\hline \multirow{6}{*}{$\begin{array}{l}\text { Universidade Federal do Pampa } \\
\text { (UNIPAMPA) }\end{array}$} & \multirow[t]{6}{*}{$\mathrm{RS}$} & Fundamentos de Administração & $4^{\circ}$ & 30 \\
\hline & & Engenharia Econômica I & $4^{\circ}$ & 30 \\
\hline & & Engenharia Econômica II & $5^{\circ}$ & 30 \\
\hline & & Contabilidade para Engenheiros & $8^{\circ}$ & 30 \\
\hline & & Custos da Produção & $9^{\circ}$ & 60 \\
\hline & & Economia Industrial & $10^{\circ}$ & 30 \\
\hline
\end{tabular}

Fonte: Os autores (2020)

No caso dos cursos de Engenharia de Produção de Santa Catarina, foram consideradas disciplinas de gestão e finanças Economia Industrial, Contabilidade Básica e Gestão de Custos, por exemplo. O quadro 2 apresenta as disciplinas selecionadas para análise (SC).

Quadro 2: Disciplinas ofertadas, carga horária e periodização nos cursos públicos de Engenharia de Produção em Santa Catarina

\begin{tabular}{|c|c|c|c|c|}
\hline $\begin{array}{c}\text { Universidades } \\
\text { Eniversidade Regional de Blumenau } \\
\text { (FURB) }\end{array}$ & SC & Disciplinas & Período & $\begin{array}{c}\text { Carga } \\
\text { Horária }\end{array}$ \\
\hline $\begin{array}{c}\text { Instituto Federal de Santa Catarina } \\
\text { (IFSC) }\end{array}$ & \multirow{2}{*}{ SC } & $\begin{array}{c}\text { Administração e } \\
\text { Organizações }\end{array}$ & $6^{\circ}$ & 80 \\
\cline { 3 - 5 } & & Economia & $3^{\circ}$ & 40 \\
\cline { 3 - 5 } & & Contabilidade Gerencial e & $7^{\circ}$ & 80 \\
\cline { 3 - 5 } & & Custos Industriais & & 80 \\
\cline { 3 - 5 } & & Gestão Financeira e Análise & $8^{\circ}$ & \\
\hline Universidade do Contestado (UNC) & SC & Administração da Produção & $1^{\circ}$ & 30 \\
\hline
\end{tabular}




\begin{tabular}{|c|c|c|c|c|}
\hline & & Economia & $4^{\circ}$ & 30 \\
\hline & & Gestão de custos & $9^{\circ}$ & 60 \\
\hline & & Gestão de investimentos & $9^{\circ}$ & 60 \\
\hline \multirow{4}{*}{$\begin{array}{c}\text { Universidade Alto Vale do Rio do } \\
\text { Peixe (UNIARP) }\end{array}$} & \multirow[t]{4}{*}{$\mathrm{SC}$} & Economia Industrial & $5^{\circ}$ & 60 \\
\hline & & Contabilidade Básica & $6^{\circ}$ & 60 \\
\hline & & Custos Industriais & $7^{\circ}$ & 60 \\
\hline & & $\begin{array}{c}\text { Finanças corporativas e } \\
\text { Análise de Investimentos } \\
\text { Industriais }\end{array}$ & $8^{\circ}$ & 60 \\
\hline
\end{tabular}

Fonte: Os autores (2020)

No caso dos cursos do estado do Paraná, foram identificadas como disciplinas de gestão e finanças Economia, Gestão Financeira e Engenharia Econômica, por exemplo, tal como consta no Quadro 3.

Quadro 3: Disciplinas ofertadas, carga horária e periodização nos cursos públicos de Engenharia de Produção no

Paraná

\begin{tabular}{|c|c|c|c|c|}
\hline Universidades & Estado & Disciplinas & Período & $\begin{array}{c}\text { Carga } \\
\text { Horária }\end{array}$ \\
\hline \multirow{4}{*}{$\begin{array}{c}\text { Universidade Federal do Paraná } \\
\text { (UFPR) }\end{array}$} & \multirow[t]{4}{*}{ PR } & Economia & $3^{\circ}$ & 60 \\
\hline & & Administração de Empresas & $4^{\circ}$ & 60 \\
\hline & & Engenharia Econômica & $5^{\circ}$ & 60 \\
\hline & & $\begin{array}{l}\text { Contabilidade de custos } \\
\text { industriais }\end{array}$ & $8^{\circ}$ & 60 \\
\hline \multirow{4}{*}{$\begin{array}{l}\text { Universidade Tecnológica Federal do } \\
\text { Paraná (UTFPR) - Londrina }\end{array}$} & \multirow[t]{4}{*}{ PR } & Introdução à Administração & $1^{\circ}$ & 60 \\
\hline & & Economia & $2^{\circ}$ & 30 \\
\hline & & Gestão de Custos & $5^{\circ}$ & 30 \\
\hline & & Engenharia Econômica & $6^{\circ}$ & 60 \\
\hline \multirow{5}{*}{$\begin{array}{l}\text { Universidade Tecnológica Federal do } \\
\text { Paraná (UTFPR) - Ponta Grossa }\end{array}$} & \multirow[t]{5}{*}{ PR } & Economia & $3^{\circ}$ & 30 \\
\hline & & Introdução à Administração & $4^{\circ}$ & 60 \\
\hline & & Gestão Financeira & $4^{\circ}$ & 60 \\
\hline & & Gestão de Custos & $5^{\circ}$ & 30 \\
\hline & & $\begin{array}{c}\text { Fundamentos de Engenharia } \\
\text { Econômica }\end{array}$ & $6^{\circ}$ & 60 \\
\hline
\end{tabular}

Fonte: Os autores (2020) 
Dentre as 10 instituições no sul do país analisadas, sendo que a UTFPR oferta dois cursos com uma estrutura curricular divergente em seus campus de Ponta Grossa e Londrina, foi possível levantar 42 disciplinas voltadas ao ensino de gestão empresarial e finanças, sendo 16 pertencentes às Universidades do Rio Grande do Sul e outras 26 divididas igualmente entre o Paraná e Santa Catarina, elencados no Gráfico 1, junto ao período em que são ministradas.

Gráfico 1: Periodização das disciplinas de Gestão e Finanças nas Universidades públicas do Sul do Brasil

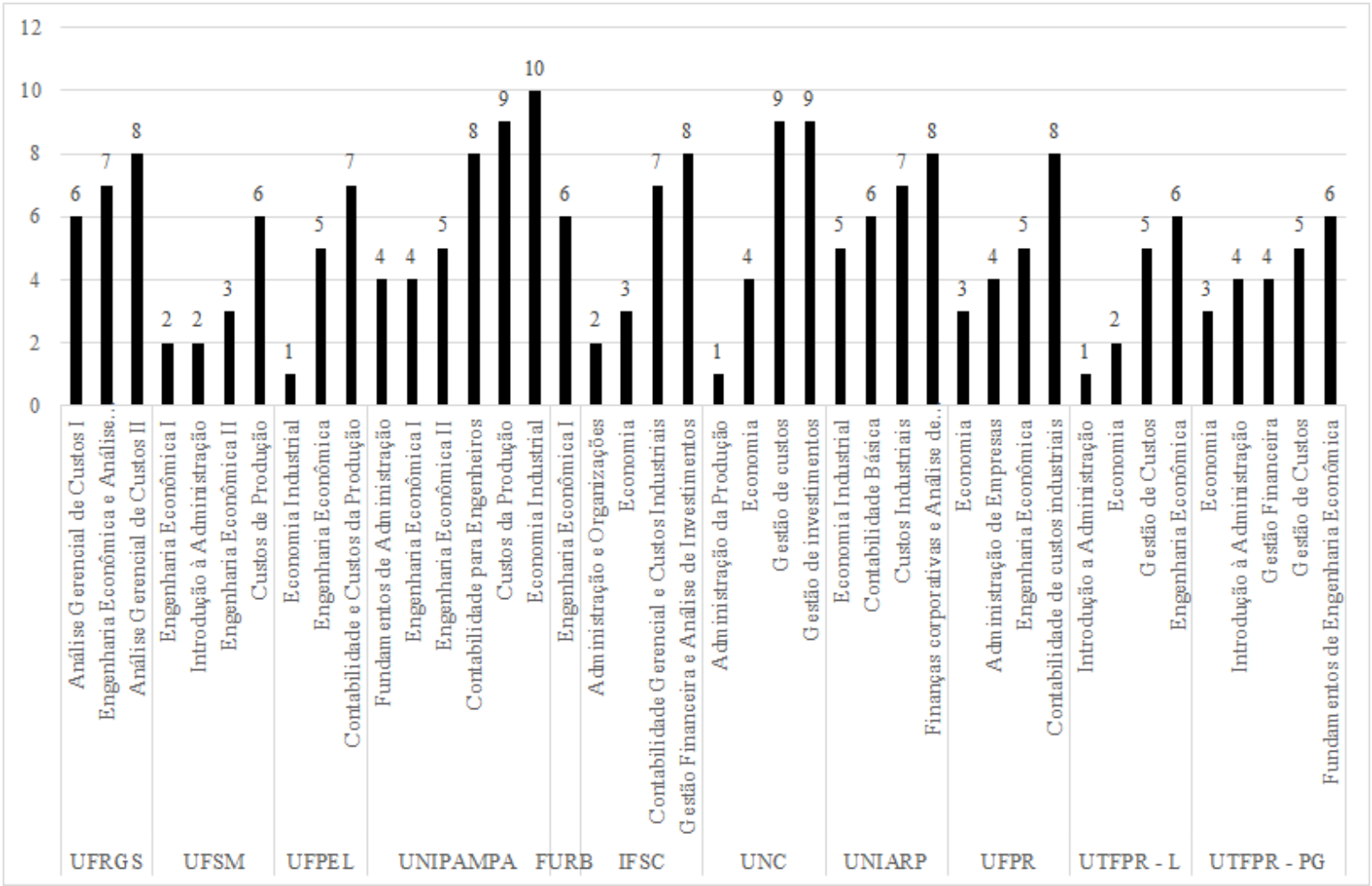

Fonte: Os autores (2020)

Embora matérias como Engenharia Econômica, Análise de Custos, Economia e Administração sejam abordadas em todas as instituições, existe um desvio padrão nos períodos em que são lecionadas. Para Economia, por exemplo, o valor chega a 2,748376, o que significa que os valores estão mais distantes da etapa da graduação em que a disciplina geralmente é apresentada aos estudantes, ou seja, da média geral dos períodos. É possível analisar, também, a amplitude do intervalo em que são abordados os conteúdos de finanças e gestão. No caso do Rio Grande do Sul, tem-se a primeira matéria, Economia Industrial na UFPel, alocada já no primeiro período, enquanto na UNIPAMPA, a mesma disciplina aparece somente no último ano da graduação, observados nos valores mínimos e máximos do Quadro 5. 
Quadro 5: Estatística descritiva para análise comparativa da periodização de disciplinas.

\begin{tabular}{|c|c|c|c|c|}
\hline Estatística & Total & $\mathbf{R S}$ & SC & PR \\
\hline Média & 5,19047619 & 5,4375 & 5,769231 & 4,307692 \\
\hline Erro padrão & 0,376792033 & 0,664384 & 0,72637 & 0,511215 \\
\hline Mediana & 5 & 5,5 & 6 & 4 \\
\hline Modo & 6 & 6 & 6 & 4 \\
\hline Desvio padrão & 2,441891462 & 2,657536 & 2,618964 & 1,843213 \\
\hline Variância da amostra & 5,962833914 & 7,0625 & 6,858974 & 3,397436 \\
\hline Curtose & $-0,875984924$ & $-0,90494$ & $-0,82015$ & 0,335901 \\
\hline Assimetria & 0,021122035 & $-0,02997$ & $-0,52554$ & 0,125629 \\
\hline Intervalo & 9 & 9 & 8 & 7 \\
\hline Mínimo & 1 & 1 & 1 & 1 \\
\hline Máximo & 10 & 10 & 9 & 8 \\
\hline Soma & 218 & 87 & 75 & 56 \\
\hline Contagem & 42 & 16 & 13 & 13 \\
\hline Nível de confiança $(95,0 \%)$ & 0,760946948 & 1,416101 & 1,582624 & 1,113843 \\
\hline
\end{tabular}

Fonte: Os autores (2020)

A média, moda e mediana obtidas apontam para uma aglomeração dos assuntos em torno do quarto ao sexto período do curso de Engenharia de Produção. A título de exemplo, tem-se o Paraná como o estado responsável por ministrar tais conteúdos ainda antes do quinto período da graduação, como pode-se observar com a média igual a 4,307692. O desvio padrão dos três estados, valor responsável por indicar a discrepância dos valores amostrais, aponta, 
novamente, uma aglomeração dos períodos em torno da média de 5,190476, pois apresenta um valor percentual baixo de $2,441891 \%$.

Já em relação a assimetria apresentada, foi possível observar que o valor calculado para Santa Catarina $(-0,52554)$ resultou em um número menor que zero o que, graficamente, implica em valores que retratam períodos mais avançados da graduação, conforme é possível analisar no Gráfico 2. No estado do Paraná, entretanto, reitera-se o contrário, ou seja, o valor de 0,125629 indica que boa parte das disciplinas se encontram na primeira metade da graduação, de acordo com o Gráfico 3.

Gráfico 2: Frequência dos períodos com disciplinas financeiras e administrativas nos cursos de Santa Catarina.

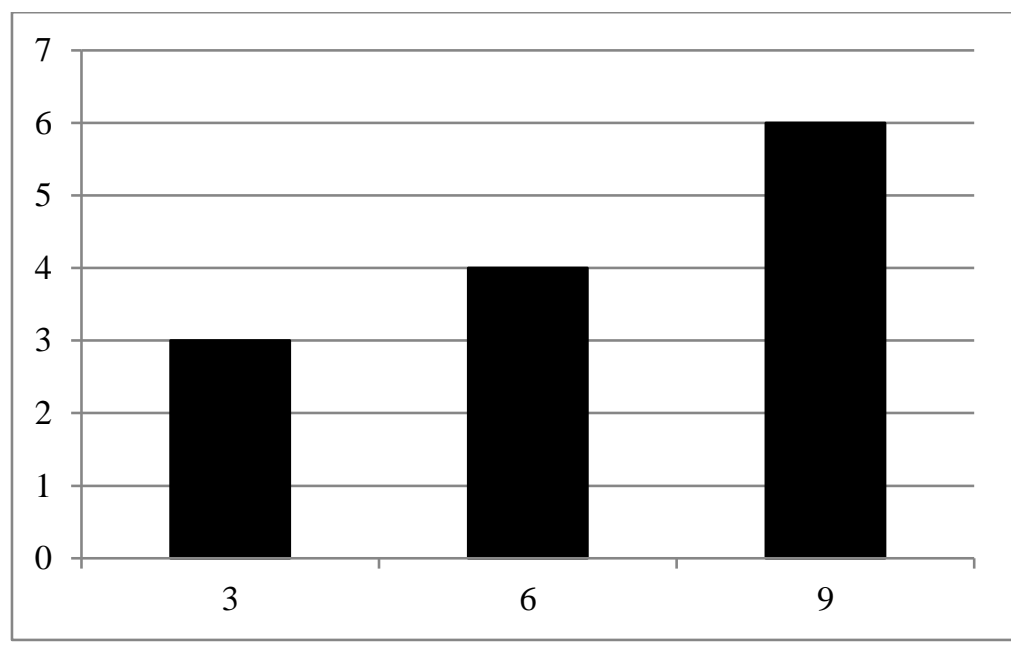

Fonte: Os autores.

Gráfico 3: Frequência dos períodos em que as disciplinas financeiras e administrativas aparecem nos cursos do Paraná.

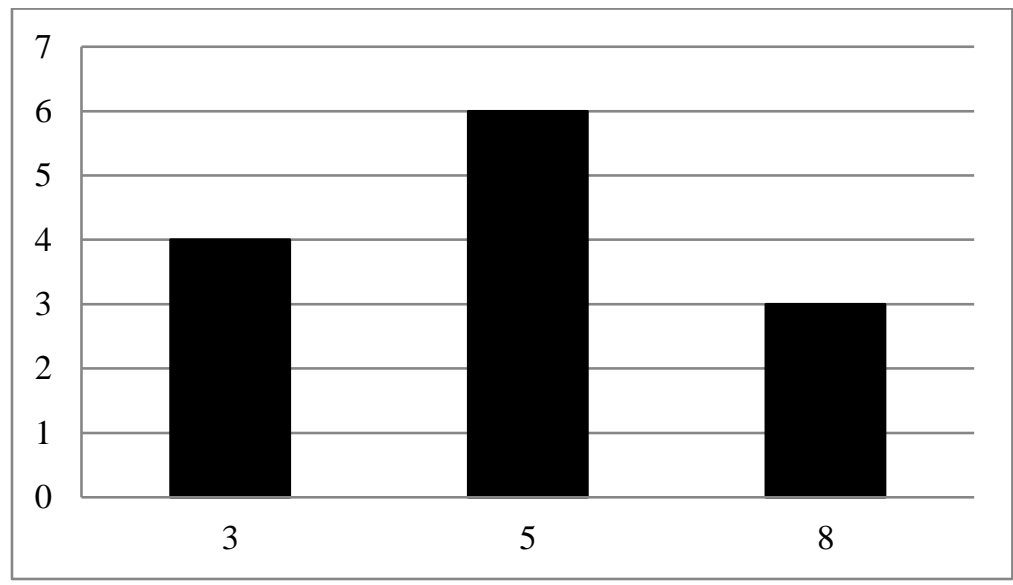

Fonte: Os autores.

Finalmente, outro cálculo estatístico que ressalta a flutuação dos valores em torno da média é a curtose. Esta determina o grau de achatamento da distribuição, ou seja, quanto maior seu 
valor, mais próximos da média estão os valores amostrais. A título de exemplo, tem-se o Paraná, com a curtose igual a 0, 335901 e o menor desvio padrão, de 1,843213.

\section{Considerações finais}

Compete à universidade garantir um engenheiro formado com o pensamento global e apto a resolver problemas. Logo, as disciplinas abordadas no decorrer do curso, bem como a ordem em que são alocadas, devem proporcionar um raciocínio crítico e garantir o entendimento pleno do que foi abordado. É de suma importância, portanto, que o conteúdo desperte a curiosidade do aluno e, para garantir este objetivo, a metodologia de ensino precisa ser diversificada, buscando métodos alternativos para a sala de aula como, por exemplo, aplicação da Taxonomia de Bloom e o uso de recursos visuais disponíveis.

O ensino de finanças e gestão para Engenharia de Produção nas Universidades do Sul do Brasil foca em disciplinas como Engenharia Econômica, Administração de Empresas, Economia e Contabilidade de Custos, sendo essas concentradas, principalmente, na metade da graduação, nos três estados. O presente artigo buscou, através de cálculos estatísticos, comparar a periodização das matérias, mas ainda é necessário debater a carga horária para cada faculdade e a ementa abordada em cada caso, visando aprimorar o perfil do profissional e garantir uma compatibilidade com o que se busca no mercado de trabalho.

No que diz respeito à comparação matéria por matéria, analisou-se uma discrepância alta em relação ao período para cada Universidade, como no caso de Economia Industrial, que aparece na UFPel logo no primeiro semestre, enquanto na UNIPAMPA, observou-se acesso ao conteúdo apenas no último momento da graduação. Ainda nesse contexto, Engenharia Econômica I aparece na maioria dos casos entre o quinto e sexto período, contudo na UFSM os alunos passam a ter seus conceitos no segundo semestre.

Finalmente, a partir dos resultados encontrados, foi possível observar a presença de tais matérias na metade da graduação para a maioria dos cursos. Além disso, o Paraná destacou-se como o estado em que as Universidades procuram lecionar economia e gestão para os alunos ainda antes da metade da graduação, ao contrário dos estados de Santa Catarina e Rio Grande do Sul. 


\section{REFERÊNCIAS}

ABEPRO - Associação Brasileira de Engenharia de Produção. Áreas da Engenharia de Produção. Disponível em: <http://www.abepro.org.br/a-profissao/\#1521896813678350bca1a-b81a>. Acesso em 04 mar. 2018.

BORGES, Fernando Hagihara; TACHIBANA, Wilson Kendy. Aspectos Importantes para o Ensino de Economia no Curso de Engenharia de Produção. Congresso Brasileiro de Ensino de Engenharia, 2004. Disponível em:

<http://www.abenge.org.br/cobenge/arquivos/15/artigos/01_432.pdf> Acesso em 06 fev. 2020.

BORREGO, Maura; KNIGHT, David B.; GIBBS JR, Kenneth; CREDE, Erin. Pursuing graduate study: factors underlying undergraduate engineering students' decisions. Journal of Engineering Education, v. 107, n. 1, p. 140-163, 2018.

BOSSHARDT, William; WALSTAD, William B. Does studying economics in college influence loan decisions later in life? The Journal of Economic Education. 2018, vol. 49, issue 2, p. 130-141 Disponível em:

<https://econpapers.repec.org/article/tafjeduce/v_3a49_3ay_3a2018_3ai_3a2_3ap_3a130141.htm> Acesso em: 07 fev. 2020.

CAIRNCROSS, Alec. Economists and Engineers. Disponível em:

<https://link.springer.com/chapter/10.1007/978-1-349-09514-8_11> Acesso em: 07 fev. 2020. Science, Politics and the Public Good. 1988, p. 203-2015.

EVANS, Emily; NACHTMANN, Heather; NEEDY, Kim A look into the engineering economy education. American Society for EngineeringEducationPaper, 2010. Disponível em:

<https://pdfs.semanticscholar.org/8da1/141190c897f72eb47e31010d907fe603b009.pdf?_ga= 2.124431433.2103233079.1581000934-42924372.1562152529> Acesso em 06 fev. 2020.

FARR, John. V.; MERINO, Donald. N., SCHAEFER, Charles, V.; Educating entry-level engineers: are broad-based business/managerial skills a key to sustaining the US innovationbased economy? International Journal of Engineering Education, v. 19, n. 2, p. 252-259, 2003.

HAYFORD, John F. The Relation of Engineering to Economics. College of Engineering Northwestern University. 1917. Disponível em <https://www.journals.uchicago.edu/doi/abs/10.1086/252928?mobileUi=0\&> Acesso em: 07 fev. 2020.

HARTMAN, Joseph C; ENKE, David. Financial Engineering: the savior or end of engineering economy? Financial Engineering : The Savior or End of Engineering Economy? American Society for Engineering Education Paper, 2007. Disponível em:

<https://pdfs.semanticscholar.org/9f80/90aeb79f411b75a34354f37d6e4797e60cfa.pdf?_ga=2.64678124.210323 3079.1581000934-42924372.1562152529> Acesso em: 06 fev. 2020.

IQBAL, Abdullah., FAROOQI, Nauman; SAUNDERS, Kent T. Teaching methods and assessment techniques used for the introductory level undergraduate finance courses in British 
and Irish universities. Journal of Economics and Finance Education, n. 5., v. 1, p. 47-61, 2006.

MELO, Jéssica Bruna de Oliveira; NETO, Miguel Elias de Oliveira; SOUZA, Vanessa Dantas de; CORREIA, Vanessa Luany Nogueira da Silva; MELO, Vivianny Crislley Gomes da Costa. Educação em Engenharia de Produção. XLIV Congresso Brasileiro De Educação Em Engenharia, 2016. Disponível em: < http://www.abenge.org.br/cobenge/arquivos/3/anais/anais/158460.pdf > Acesso em: 06 fev. 2020.

MELLO, José André Villas Boas; SANTOS, Vivian Janachevitz Duarte dos. A formação acadêmica em Engenharia de Produção, a demanda do mercado e as unidades curriculares de Instituições de Educação Superior públicas do Rio de Janeiro. Disponível em: <https://doi.org/10.5585/exactaep.v13n1.5349> Acesso em: 06 fev. 2020. Exacta, p. 13(1), 2015.

PIRATELLI, Claudio Luis. A Engenharia de Produção no Brasil. Congresso Brasileiro de Ensino de Engenharia, XXXIII. 2005. Disponível em <http://www.abenge.org.br/cobenge/arquivos/14/artigos/SP-15-250463528181117717074687.pdf> Acesso em: 07 fev. 2020.

RUF - Ranking Universitário Folha. Ranking de cursos de graduação. Disponível em: $<$ https://ruf.folha.uol.com.br/2019/ranking-de-cursos/engenharia-de-producao/> Acesso em 19 dez. 2019.

SÁ, Klitia Valeska Bicalho de. O ensino de economia nos cursos de engenharia: reflexões e um estudo de caso. Congresso Brasileiro de Educação em Engenharia, 2014. Disponível em: < http://www.abenge.org.br/cobenge/arquivos/5/Artigos/130468.pdf> Acesso em: 06 fev. 2020 .

SAUNDERS, L. Ken Lauderbaugh; SAUNDERS, Joan. G. (2004). House of Quality Assessment of Business Skills required by Manufacturing Engineering Graduates. International Journal of Engineering Education, 20(5), 777-786. Disponível em: <https://www.ijee.ie/articles/Vol20-5/IJEE1515.pdf> Acesso em: 06 fev. 2020.

SIEGFRIED, John J.; BARTLETT, Robin L.; HANSEN, W.Lee; KELLEY, Allen C.; MCCLOSKEY, Donald N.; TIETENBERG, Thomas H. The Status and Prospects of the Economics Major. Jour-nal of Economic Education. Summer 1991, 22(3), p. 197-224.

SILVA, Antônio Marcos Rodrigues; STANO, Rita de Cássia Magalhães Trindade; REZENDE, Marcelo Lacerda. Análise do ensino de Teoria Econômica nos cursos de Engenharia de Produção em seus aspectos curriculares. Revista Produção Online. 2012, vol.12, n.2, p.480-498.

ZOGHI, Shervin. Engineering Economics and its role in the engineering curricula. American Society for Engineering Education Paper, 2015. Disponível em: <https://pdfs.semanticscholar.org/9f80/90aeb79f411b75a34354f37d6e4797e60cfa.pdf?_ga=2. 64678124.2103233079.1581000934-42924372.1562152529> Acesso em: 06 fev. 2020. 